\title{
MOLECULAR PHYLOGENETICS OF STENOCIONOPS DESMAREST, 1823 (CRUSTACEA: DECAPODA: BRACHYURA)
}

\author{
Colavite, J. ${ }^{1,2,}$; Windsor, A.M. ${ }^{3}$ \& Santana, W. ${ }^{2}$ \\ ${ }^{1}$ São Paulo State University (UNESP), campus Botucatu, Programa de Pós-Graduação em Zoologia. \\ ${ }^{2}$ Universidade do Sagrado Coração (USC), Bauru, Pró-Reitoria de Pesquisa e Pós-Graduação, \\ Laboratório de Sistemática Zoológica (LSZ). \\ ${ }^{3}$ National Museum of Natural History, Smithsonian Institution (NMNH), Department of Invertebrate Zoology. \\ *Corresponding author: jessica.colavite@gmail.com \\ The Amphi-American genus of spider crabs Stenocionops Desmarest, 1823 is composed of 10 valid species, \\ seven of which are extant. Morphological similarities between species during ontogenetic development can \\ make proper species identification difficult and has resulted in taxonomic uncertainties. A previous molecular \\ phylogeny showed that Stenocionops is genetically allied to the family members of the subfamily Pisinae \\ (i.e., Macrocoeloma, Leptopisa, Libinia, Pricoceroides) within the family Epialtidae. This study investigates the \\ interspecific relationships in Stenocionops for the first time and aims to clarify the taxonomic position of genus. \\ A phylogenetic tree was built using a concatenated alignment of three mitochondrial genes (COI, 16S rRNA \\ and $12 \mathrm{~S}$ rRNA) using maximum likelihood and Bayesian inference methods. We successfully sequenced six of \\ the seven extant species. Within the context of Majoidea, the phylogenetic tree supported Stenocionops as a \\ monophyletic clade positioned as a sister to Picroceroides a well-supported clade composed of ((Notolopas + \\ Leptopisa) (Picroceroides + Stenocionops)).
}

Keywords: Majoidea, spider crabs, rRNA, DNA barcode, Epialtidae.

Financial support: Fapesp 2017/08969-1. 